\section{Low-volume Sprays to Treat Fresh-sliced Apples with Anti-browning Solution}

\author{
Peter M.A. Toivonen ${ }^{1}$ and Pascal Delaquis
}

\begin{abstract}
AdDitional Index wORDs. Malus $\times$ domestica, fresh-cut, sanitation, vanillin
Summary. Use of sprays to sanitize and treat apple (Malus $\times$ domestica) slices helps to reduce the potential for cross-contamination that can occur when treatments are done in dip tanks. This research examined several factors that may affect the efficacy of spray treatments: 1) spray volume; 2) efficacy of spray application of anti-browning solution (ABS) compared with dipping; 3 ) effect of slice density during spraying; and 4) effect of the addition of an antimicrobial compound, vanillin, on microbiologically associated browning. Low-volume sprays (36-50 $\mathrm{mL} \cdot \mathrm{kg}^{-1}$ slices) of ABS gave maximal control of browning and this was equivalent to the control afforded by a 2 -minute dip in the ABS. Spray application resulted in significant reduction in incidence and severity of microbiologically associated "secondary browning" as compared with dip application. However, if more than one layer of slices were present on the support mesh during the spray treatment, then secondary browning increased. This was attributed to potential cross-contamination between layers of apples in the spray treatment. Addition of vanillin into the ABS resulted in a $50 \%$ reduction of the incidence of "secondary browning." Low-volume spray applications of ABS can be managed such that the microbiologically associated "secondary browning" is much lower than possible with dip application.
\end{abstract}

$\mathrm{T}$ The development of the freshcut fruit category is rapid, with sales in excess of $\$ 1$ billion US expected by 2008 (Clement, 2004). Fresh-cut vegetable products have enjoyed strong growth in the past and many of the technical issues have been overcome. However, technical issues are more difficult to overcome in the fruit category and research is required to resolve them effectively. One of the limitations of fresh-cut fruit products is that they are processed in a ripe stage, making them more susceptible to quality deterioration once they are cut and packaged (Toivonen and DeEll, 2002).

The most critical issue with freshcut fruit products is sanitation after it is cut. The challenge is brought about since fruit is fresh-cut at a mature, ripe stage as opposed to an immature or vegetative stage as is the case with fresh-cut vegetables (Toivonen and Beveridge, 2005); ripe fruit has high

Agriculture and Agri-Food Canada, Pacific Agri-Food Research Centre, Box 5000, 4200 Highway 97, Summerland, British Columbia, Canada VOH 1Z0.

${ }^{1}$ Corresponding author; e-mail: toivonenp@agr.gc.ca; phone: 250.494 .6386

Acknowledgments. The authors would like to thank Keith Walsh and Karen Rivest for their technical assistance, and the Washington Tree Fruit Research Commission and Agriculture and Agri-Food Canada's Matching Investment Initiative for their financial support. sugar, organic acid, and polyphenol content. When cut fruit is placed into a wash tank for sanitation and/or postcutting treatment (e.g., anti-browning treatment), the high organic load of the sugars, acids, and polyphenols from the cut edges can quench sanitizing agents very rapidly (Delaquis et al., 2004). Hence, microorganisms can accumulate in wash tanks and treatment tanks. This leads to a high potential for cross-contamination of product introduced into the wash or treatment tank. A phenomenon, coined "secondary browning," has been identified as a consequence of cross-contamination between fresh-sliced apples washed and treated in the same dip tank (Toivonen et al., 2003). It is a problem that occurs in commercial production and is considered to be due to fungal spores derived from the fruit (Toivonen et al., 2003).

One approach considered an option to prevent cross-contamination during sanitizing and treatment of apples was that of spray technology (Beuchat et al., 1998). In this approach, product is passed through a spray tunnel on a wire conveyor belt, allowing the product to be completely washed and then allowing the wash water to drain off without touching another slice. The risk of cross-contamination is avoided. Work in this paper is presented on critical parameters in the development of a spray treatment line with consideration of success based on the effect of each parameter on both cut-edge browning and secondary browning in fresh-cut apple slices.

\section{Materials and methods}

Fruit HANDLING AND PROCESSING. 'Delicious' apples were obtained throughout the storage season beginning on 22 Nov. 2002 and until 21 Aug. 2003 from Brewster Heights Packinghouse, Brewster, Wash. In that state the recommendations are to harvest 'Delicious' apples at $17 \mathrm{lbf}$ firmness, $10 \%$ soluble solids, $0.27 \%$ acidity, and at a starch index of 1.6 (on a 1-6 scale) and to store short term in refrigerated rooms set at 32 ${ }^{\circ} \mathrm{F}$ (or slightly lower) or long term in controlled atmosphere rooms with $1.5 \%$ oxygen and up to $2 \%$ carbon dioxide and at a temperature of 32 to $34^{\circ} \mathrm{F}$ (Kupferman, 2002). Fruit were picked up from the Brewster Heights Packinghouse and transported within $3 \mathrm{~h}$ to the Agriculture and Agri-Food Research Centre at Summerland, B.C., via refrigerated truck set at $1{ }^{\circ} \mathrm{C}$. Fruit were held at $1{ }^{\circ} \mathrm{C}$ storage for a maximum of 2 weeks until they were used in experiments.

\begin{tabular}{llll}
\hline $\begin{array}{l}\text { Units } \\
\begin{array}{l}\text { To convert U.S. to SI, } \\
\text { multiply by }\end{array}\end{array}$ & U.S. unit & SI unit & $\begin{array}{l}\text { To convert SI to U.S., } \\
\text { multiply by }\end{array}$ \\
\hline 29.5735 & $\mathrm{fl} \mathrm{oz}$ & $\mathrm{mL}$ & 0.0338 \\
318.3268 & $\mathrm{fl} \mathrm{oz} / \mathrm{ft}^{2}$ & $\mathrm{~mL} \cdot \mathrm{m}^{-2}$ & 0.0031 \\
65.1985 & $\mathrm{fl} \mathrm{oz} / \mathrm{lb}$ & $\mathrm{mL} \cdot \mathrm{kg}^{-1}$ & 0.0153 \\
3.7854 & $\mathrm{gal}$ & $\mathrm{L}$ & 0.2642 \\
2.5400 & inch $(\mathrm{es})$ & $\mathrm{cm}$ & 0.3937 \\
6.4516 & inch & $\mathrm{cm}^{2}$ & 0.1550 \\
0.4536 & $\mathrm{lb}$ & $\mathrm{kg}$ & 2.2046 \\
4.4482 & $\mathrm{lbf}$ & $\mathrm{N}$ & 0.2248 \\
7.4892 & $\mathrm{oz} / \mathrm{gal}$ & $\mathrm{g} \cdot \mathrm{L}^{-1}$ & 0.1335 \\
0.001 & $\mathrm{ppm}$ & $\mathrm{g} \cdot \mathrm{L}^{-1}$ & 1000 \\
1 & $\mathrm{ppm}$ & $\mu \mathrm{L} \cdot \mathrm{L}^{-1}$ & 1 \\
6.8948 & $\mathrm{psi}$ & $\mathrm{kPa}$ & 0.1450 \\
$\left({ }^{\circ} \mathrm{F}-32\right) \div 1.8$ & ${ }^{\circ} \mathrm{F}$ & ${ }^{\circ} \mathrm{C}$ & $\left(1.8 \times{ }^{\circ} \mathrm{C}\right)+32$ \\
& & &
\end{tabular}


Apple fruit were cut using a hand-operated Food Prep bench-top corer-wedger (Ditto Dean, Rocklin, Calif.) fitted with an eight-slice wedging/coring head. Apple slices were cut as described below in the various experiments and bulked. Slices were then selected randomly from the bulked slices and placed into replicate bags.

INITIAL TRIAL WITH HAND SPRAYER. To expedite the setup of a spray tunnel and purchase appropriate spray hardware, it was essential to estimate the minimum volume of spray required to control cut-edge browning. This experiment was conducted using a hand-spray bottle (Nalgene 200-mL aerosol spray bottle; Fisher Scientific, Mississauga, Ont., Canada) set on misting mode. An ABS containing $70 \mathrm{~g} \cdot \mathrm{L}^{-1}$ Nature Seal (Mantrose-Haueser Co., Westport, Conn.) was prepared using distilled water at room temperature. For each treatment and replicate, $1 \mathrm{~kg}$ of apple slices was laid on a reinforced vinyl mesh affixed to a plastic frame to allow drainage of the treated slices. The apple slices were sprayed with half of the target volume and then turned over to the opposite surface, and the second half of the volume was then applied. After the slices were allowed to drain for $2 \mathrm{~min}$ at room temperature, they were placed in $10 \times 6$-inch PD900 plastic film bags (oxygen transmission rate $=3000 \mathrm{~mL} \cdot \mathrm{m}^{-2}$ per 24 h; Cryovac Division, W.R. Grace \& Co., Canada Ltd., Mississauga, Ont.)], which were then heat-sealed and placed into a $5{ }^{\circ} \mathrm{C}$ room for $7 \mathrm{~d}$. Twenty-six slices were placed into each bag (replicate), and there were a total of four replicates per treatment in each experiment from a total number of 112 fruit. Apple slices, within a treatment, were selected at random from a bulk bin after slicing and treatment. The experiment was conducted twice. At $7 \mathrm{~d}$ the slices were removed from the bags and lightness values determined as described below.

CONTINUOUS, LOW-VOLUME SPRAY APPARATUS. A fine misting spray was achieved using Naan-Dan fogging nozzles (black nozzle; Point Source Irrigation, Fresno, Calif.), calibrated to emit $300 \mathrm{~mL} \cdot \mathrm{min}^{-1}$ at a pressure of 18 psi. See Fig. 1 for a schematic drawing of the spray setup. Spray nozzles were set at a distance of $30 \mathrm{~cm}$ from the apple slices. Apple slices were supported on a reinforced vinyl mesh that was affixed to a plastic frame, allowing uniform exposure to the spray from top and bottom and unimpeded drainage of excess spray from treated slices. Sanitizer and $\mathrm{ABS}$ was fed to the spray nozzles with a Model QB direct current drive fitted with a Q2 sanitary pump head (Fluid Metering Inc., Syosset, N.Y.). Pump speed was controlled by a model V200 Stroke Rate Controller(Fluid Metering Inc.) set at $66.6 \%$ of maximum flow. The sprayer unit was started up before apple slices were introduced into the spray tunnel to ensure a uniform and repeatable exposure to the spray. Spray pattern from the nozzles was such that it provided uniform coverage of the whole area of the mesh that was supporting the apple slices during treatment. Solutions applied through the sprayer were only used once.

DWELL TIME UNDER SPRAY. Slices were held in the spray tunnel for 0 , $5,10,20 \mathrm{~s}$ with the calibrated spray volume of $300 \mathrm{~mL} \cdot \mathrm{min}^{-1}$. Once the time had elapsed for each treatment, the reinforced vinyl mesh support that held the slices was removed from the spray tunnel and allowed to drain for $2 \mathrm{~min}$, after which they were placed into $10 \times 6$-inch packages made with PD900 film. Dip control samples (4-kg slices) were sliced and dipped in $3 \mathrm{~L}$ of ABS $\left(70 \mathrm{~g} \cdot \mathrm{L}^{-1}\right.$ Nature Seal in water $)$ for $2 \mathrm{~min}$. Dipped slices were allowed to drain for $2 \mathrm{~min}$ prior to placement into PD900 film bags. Twenty-six slices were placed into each bag (replicate) and there were a total of four replicates per treatment from a total number of 80 fruit. Apple slices, within a treat-

ment, were selected at random from a bulk bin after slicing and treatment. The experiment was conducted twice. The surface lightness of each slice was assessed after $7 \mathrm{~d}$ storage at $5^{\circ} \mathrm{C}$, using the method as described below.

EFFECT OF DIP VS. SPRAY ON SECONDARY BROWNING. 'Delicious' apple slices (Brewster Heights Packing, Brewster, Wash.) were either dipped in ABS ( $70 \mathrm{~g} \cdot \mathrm{L}^{-1}$ Nature Seal in water) for 2 min or sprayed for $10 \mathrm{~s}$ with the same concentration of ABS using the spray apparatus described above. Slices were then mixed to randomize and then packaged in PD900 bags and sealed using a Swiss Vac vacuum sealer (Neue Transvac Maschinen AG, Lucern, Switzerland). Bags were then stored at $5{ }^{\circ} \mathrm{C}$ for 7,14 , and $21 \mathrm{~d}$. A sample of freshly cut, unbagged slices was set aside and evaluated immediately. On each sampling day the bags were removed from storage, opened, and evaluated visually for secondary browning and surface lightness as described below. Twenty-six slices were placed into each bag (replicate) and there were a total of seven replicates per treatment in each experiment from a total number of 224 fruit. Apple slices, within a treatment, were selected at random from a bulk bin after slicing and treatment. The experiment was conducted twice.

EFFECT OF NUMBER OF SLICES PER UNIT AREA ON SECONDARY BROWNING. The effect that the number of slices per area had on the effectiveness of spray washing and application of ABS

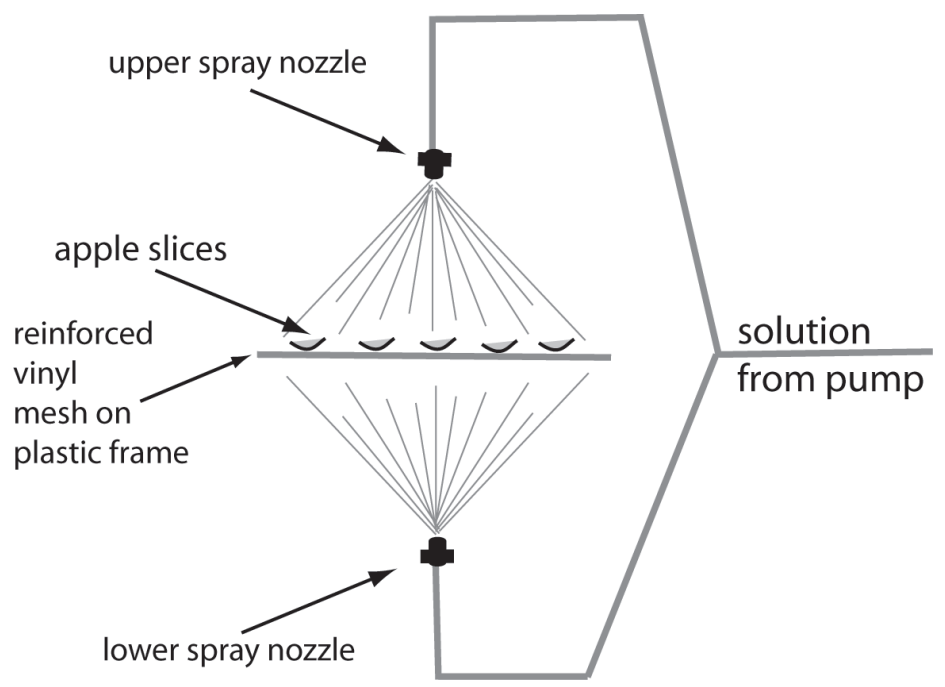

Fig. 1. A schematic representation of the low-volume spray apparatus for applying anti-browning spray solution to fresh-cut 'Delicious' apple slices. Note the spray nozzles (both upper and lower) are positioned $30 \mathrm{~cm}$ (11.8 inches) from the slices as they lay on the vinyl supporting mesh. 
was tested in an experiment where differing numbers of slices were placed onto a known area of screen. The ABS (70 g. $\mathrm{L}^{-1}$ Nature Seal) was applied as a 10-s spray in all treatments. Screen area was calculated to be $1018 \mathrm{~cm}^{2}$ and the areas covered by 40,80 , and 120 slices were calculated to be 525,1050 , and $1576 \mathrm{~cm}^{2}$, respectively. Ratios of slice surface area to screen surface area were then calculated to be $0.5: 1$, $1: 1$, and $1.5: 1$ for the slices from 40 , 80 , and 120 slices, respectively. This would represent three scenarios on a conveyor line from a sparsely covered line, to a fully covered line, to a line where at least two layers of slices occur over part of the surface area. The last situation would be one where some cross-contamination is expected from slice to slice. Slices were then mixed to randomize and then packaged in PD900 bags. Twenty-six slices were placed into each bag (replicate), and there were a total of four replicates per treatment in each experiment from a total number of 144 fruit. Apple slices, within a treatment, were selected at random from a bulk bin after slicing and treatment. The experiment was conducted twice. At each sampling day the bags were removed from storage, opened, and evaluated visually for secondary browning and surface lightness as described below.

INCORPORATION OF A NATURAL ANTIMICROBIAL INTO THE ANTI-BROWNING SOLUTION. As a further step to control fungal growth on the cut slices, a natural antifungal agent, vanillin (Fitzgerald et al., 2005; López-Malo et al., 1995), was incorporated into the ABS (70 $\mathrm{g} \cdot \mathrm{L}^{-1}$ Nature Seal) at $7.6 \mathrm{~g} \cdot \mathrm{L}^{-1}$. Three treatments were compared: 1) 10-s spray of $A B S$ applied immediately after cutting; 2) 30-s spray with $100 \mu \mathrm{L} \cdot \mathrm{L}^{-1}$ chlorine, followed by a 10-s spray of ABS solution; and 3) 30-s spray with $100 \mu \mathrm{L} \cdot \mathrm{L}^{-1}$ chlorine, followed by a 10 -s spray of ABS solution into whichvanillin was incorporated. Twenty-six slices were placed into each bag (replicate) and there was a total of four replicates per treatment in each experiment from a total number of 72 fruit. Apple slices, within a treatment, were selected at random from a bulk bin after slicing and treatment. The experiment was conducted twice. At each sampling day the bags were removed from storage, opened, and evaluated visually for secondary browning and surface lightness as described below.
LIGHTNESS VALUE DETERMINATION FOR CUT-EDGE BROWNING. Efficacy in control of cut-edge browning was assessed at $7 \mathrm{~d}$, since through experience, cut-edge browning control was found to be stable between 7 to $21 \mathrm{~d}$ after cutting (Toivonen et al., 2003). Lightness value for each slice was determined using a Minolta chromameter (CR300; Minolta, Ramsey, N.J.) using the $L^{*}$ values of the Commision Internationale de l'Eclairage (CIE) color system (Gil et al., 1998). It was determined at three points on each side of the slice (near the calyx end, in the middle, and near the stem end) to give six values per slice. These six values per slice were averaged into one value. The average for all slices within a bag (replicate) was used as the single replicate value in statistical analysis.

SECONDARY BROWNING DETERMinATION. The level of secondary browning could not be determined using a chroma-meter since it occurs sporadically and on localized areas on the slice surface. Hence a visual rating for level of secondary browning was developed. The scale used had three points; 1 = no browning present; 2 = few light brown spots visible; and $3=$ many dark brown spots visible.

Statistical analysis. Data from the hand spray and the dwell time experiments were analyzed using nonlinear regression procedures from Sigma Plot, using an "exponential rise to a maximum" model (version 8.02; SPSS Inc., Chicago). Data are presented as means with standard deviations with the fitted curve, both of which were determined from the raw data set. Data from the comparison of dip vs. spray and slice number per area experiments were analyzed as a randomized complete-block design using the General Linear Models procedure (SAS Institute, Cary, N.C.), with treatment and time as the independent variables. All treatment effects were found to be significant at the $P$ $<0.05$ level. Results are presented as means with SE values. Incorporation of the antimicrobial experiment was analyzed in a similar fashion, except that the treatment effect was the only independent variable tested.

\section{Results and discussion}

INITIAL TRIAL WITH HAND SPRAYER. An ABS volume of $36 \mathrm{~mL} \cdot \mathrm{kg}^{-1}$ slices provided maximal control of cut-edge browning when medium-sized apples were cut into eighths (Fig. 2). No further benefit was achieved in controlling cut-surface browning in apple slices when larger volumes were used. The level of control in cut-edge browning with $36 \mathrm{~mL} \cdot \mathrm{kg}^{-1}$ slices or more of ABS was equivalent to that achieved with a 2-min dip using the same ABS concentration (data not shown).

DWELL TIME UNDER SPRAY. In a separate experiment, where a fixed

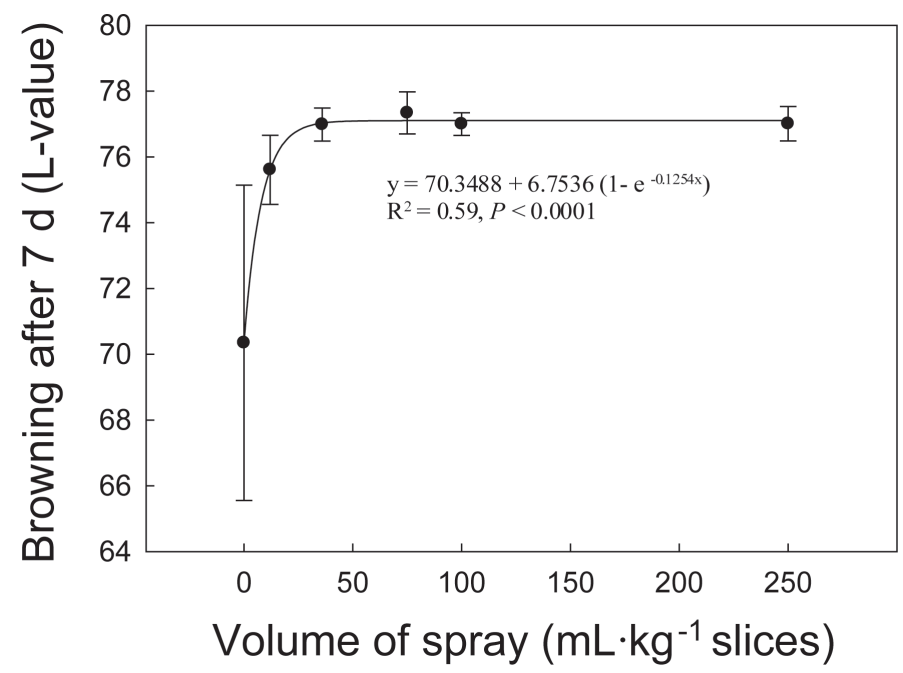

Fig. 2. Effect of spray volume of anti-browning solution (ABS) [70 g. $\mathrm{L}^{-1}(9.3$ $\mathrm{oz} / \mathrm{gal}$ ) Nature Seal] on cut-surface browning when hand-sprayed onto $1 \mathrm{~kg}$ $(2.2 \mathrm{lb})$ of sliced 'Delicious' apples. Note that one-half of each spray volume was applied to one side of the slices, they were then flipped over and the second half of the spray volume applied. Cut-surface browning was determined by measuring lightness (L-value) with a Minolta chroma-meter $7 \mathrm{~d}$ after cutting and storage at $5{ }^{\circ} \mathrm{C}\left(41.0^{\circ} \mathrm{F}\right)$. Error bars represent SD of the mean, $\mathrm{n}=8 ; 1 \mathrm{~mL} \cdot \mathrm{kg}^{-1}=0.0153 \mathrm{fl}$ $\mathrm{oz} / \mathrm{lb}$. 
sprayer was used to apply ABS to the top and bottom of the slices simultaneously, it was determined that a 10 -s dwell time provided maximal benefit (Fig. 3). At dwell times of 10 s or more, the control of browning was similar to that achieved using a 2 -min dip in the same solution (data not shown). When calculated, a 10-s dwell time is equivalent to $50 \mathrm{~mL} \cdot \mathrm{kg}^{-1}$ slices. This is very close to the minimum effective volume found in the hand-sprayer experiment. These two experiments confirm that a minimum of between 36 and $50 \mathrm{~mL} \cdot \mathrm{kg}^{-1} \mathrm{ABS}$ were required to effectively control cut-edge browning in apple slices.

EFFECT OF DIP VS. SPRAY ON SECONDARY BROWNING. Spray application ABS was found to lead to lower levels of secondary browning in the apple slices tested (Fig. 4). Secondary browning was not apparent until the third week of storage at $5{ }^{\circ} \mathrm{C}$ for both the dip and the spray treatments. However, the severity of the secondary browning was greater in the slices from the dip treatment. Despite the fact that secondary browning was greater in the dip treatment, the cut-edge browning was controlled by either the 2-min dip or the 10-s spray application of ABS (Fig. 4). These results support the prior observation that while the dip treatment approach can control cut-edge browning effectively, when larger volumes of slices are treated in the same dip, the cross-contamination between slices during the treatment process leads to significant levels of secondary browning (Toivonen et al., 2003).

EFFECT OF NUMBER OF SLICES PER UNIT AREA ON SECONDARY BROWNING. This experiment showed that once apple slices are crowded such that they more than cover belt area, that crosscontamination problems increased (Fig. 5). Only when slice area exceeded the area on the screen (coverage ratio of 1.5:1 or 120 slices) was there an increase in secondary browning on the packaged slices after 3 weeks storage at $5{ }^{\circ} \mathrm{C}$. Response cannot be attributable to lack of ABS contact with cut slice surfaces, since an analysis of the cut-edge browning after $7 \mathrm{~d}$ in storage showed no increase as slice number increased. It is common that product can be crowded onto conveyer belts during a processing run; however, these results show that cross-contamination of slices can occur when slices exceed one layer in depth. Therefore, it is important to

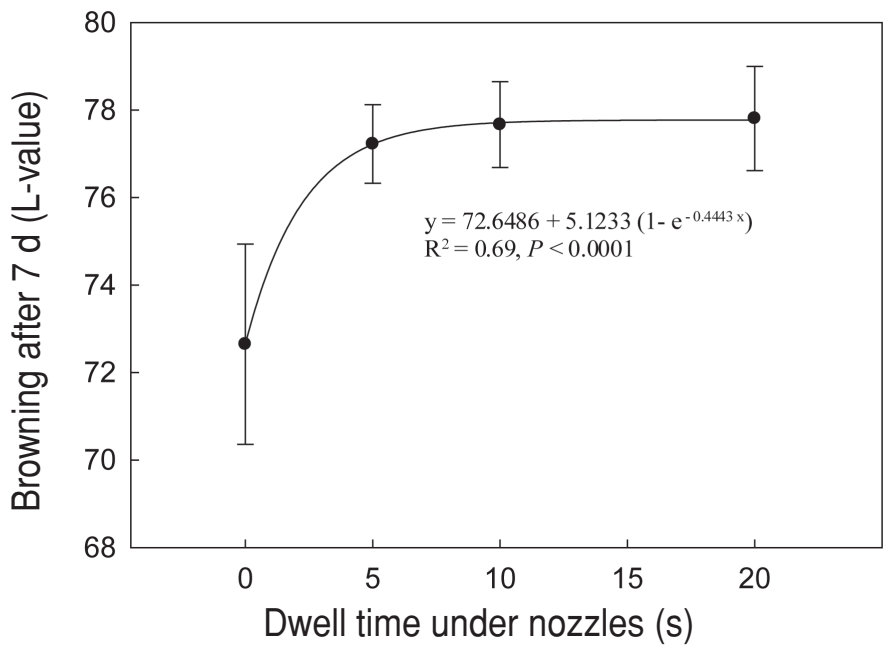

Fig. 3. Effect of dwell time under the spray apparatus (Fig. 1) on cut-surface browning of 'Delicious' apple slices when anti-browning solution (ABS) [70 $\mathrm{g} \cdot \mathrm{L}^{-1}(9.3 \mathrm{oz} / \mathrm{gal})$ Nature Seal] was sprayed at a rate of $300 \mathrm{~mL} \cdot \mathrm{min}^{-1}(10.1 \mathrm{fl}$ $\mathrm{oz} / \mathrm{min}$ ). Cut-surface browning was determined by measuring lightness (L-value) with a Minolta chroma-meter $7 \mathrm{~d}$ after cutting and storage at $5{ }^{\circ} \mathrm{C}\left(41.0{ }^{\circ} \mathrm{F}\right)$. Error bars represent SD of the mean, $\mathbf{n}=8$.

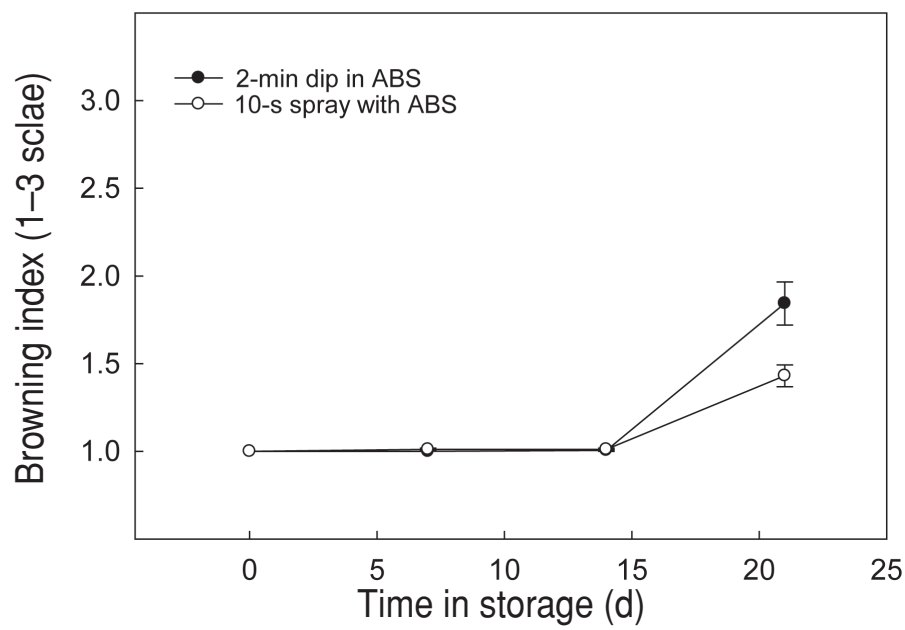

Fig. 4. Differences in cut-edge browning and secondary browning for 'Delicious' apple slices treated with either a 2 -min dip in anti-browning solution (ABS) [70 $\mathrm{g} \cdot \mathrm{L}^{-1}(9.3 \mathrm{oz} / \mathrm{gal})$ Nature Seal] or a 10 -s spray with the same solution. Note cut-edge browning was determined by measuring lightness (L-value) with a Minolta chroma-meter after $7 \mathrm{~d}$ storage at $5{ }^{\circ} \mathrm{C}\left(41.0^{\circ} \mathrm{F}\right)$ and secondary browning assessed visually after $21 \mathrm{~d}$ storage at the same temperature. Error bars (where visible) represent $\mathrm{SE}$ of the mean, $\mathrm{n}=14$.

understand that the spray approach can only work if product volume management ensures that crowding on belts does not occur.

INCORPORATION OF A NATURAL ANTIMICROBIAL INTO THE ANTI-BROWNING sOLUTION. When vanillin was added $\left(7.6 \mathrm{~g} \cdot \mathrm{L}^{-1}\right)$ to the ABS in the spray, the severity of secondary browning decreased to at least half of what was found in the control spray (Fig. $6)$. This is not surprising as vanillin is known to be a good antimicrobial effective against many fungi (Fitzger- ald et al., 2005; López-Malo et al., 1995), despite the fact that the mode of action is not completely understood (Fitzgerald et al., 2005). The severity of secondary browning was higher in the chlorine $+\mathrm{ABS}$ treatment, which may seem counterintuitive. However, the ABS treatment contains significant quantities of ascorbic acid as an active ingredient, and ascorbic acid is both organic and antioxidant in nature. Since chlorine action is based on oxidation (Delaquis et al, 2004), the chlorine residue on the slices when they were 


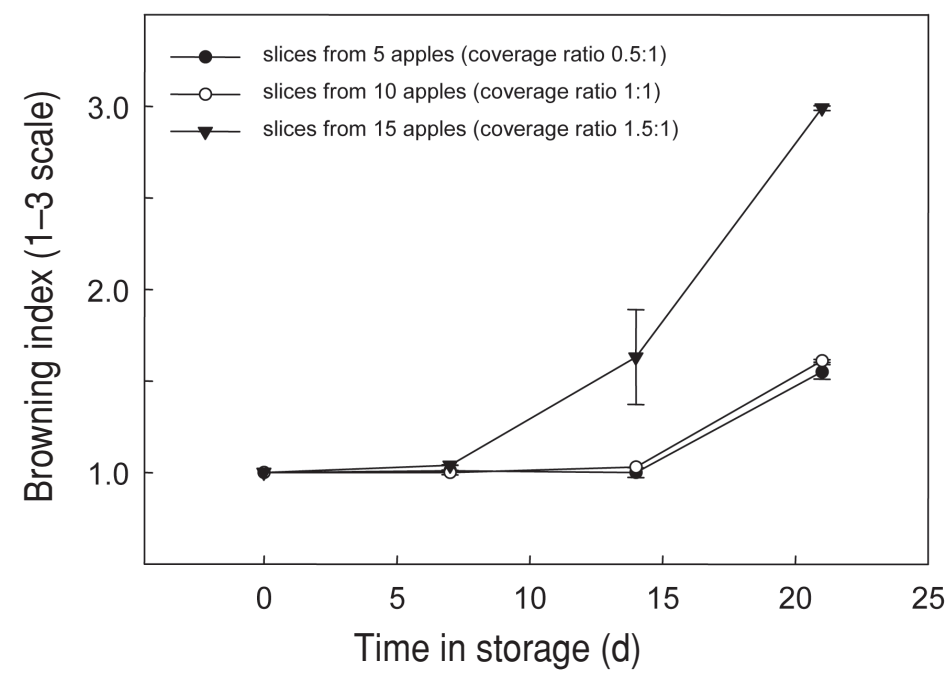

Fig. 5. Changes in secondary browning over $21 \mathrm{~d}$ storage at $5{ }^{\circ} \mathrm{C}\left(41.0{ }^{\circ} \mathrm{F}\right)$ for 'Delicious' apple slices treated with a 10 -s spray of anti-browning solution (ABS) $\left[70 \mathrm{~g} \cdot \mathrm{L}^{-1}(9.3 \mathrm{oz} / \mathrm{gal})\right.$ Nature Seal $]$ at three different apple slice area to supporting mesh surface area ratios $(0.5: 1,1: 1$, and 1.5:1). See Fig. 1 and the materials and methods section for full details. Secondary browning was assessed using a three-point scale: 1 = no browning present; 2 = few light brown spots visible; and $3=$ many dark brown spots visible. Error bars (where visible) represent SE of the mean, $\mathbf{n}=8$.

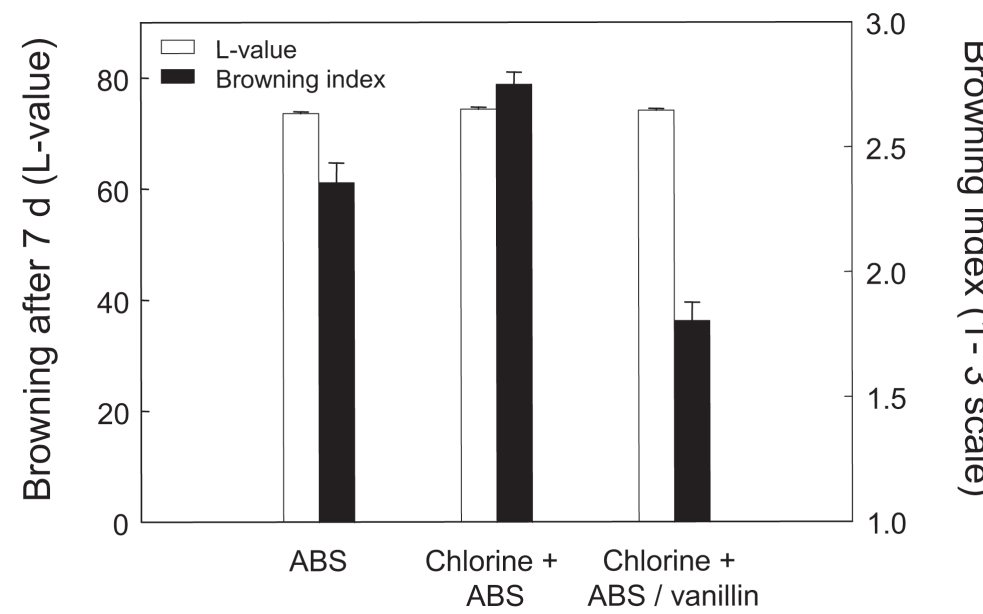

Fig. 6. Differences in cut-edge browning and secondary browning for 'Delicious' apple slices treated with 1 ) a 10 -s spray of anti-browning solution (ABS) $\left[70 \mathrm{~g} \cdot \mathrm{L}^{-1}(9.3 \mathrm{oz} / \mathrm{gal})\right.$ Nature Seal $\left.] ; 2\right)$ a $30-\mathrm{s}$ chlorine spray wash $\left[100 \mu \mathrm{L} \cdot \mathrm{L}^{-1}\right.$ (ppm)] and then a 10-s spray with anti-browning solution (ABS); or 3) a 30-s chlorine spray wash and then a 10-s spray with the ABS supplemented with 7.5 $\mathrm{g} \cdot \mathrm{L}^{-1}(7500 \mathrm{ppm})$ vanillin. Note cut-edge browning was determined by measuring lightness (L-value) with a Minolta chroma-meter after $7 \mathrm{~d}$ storage at $5{ }^{\circ} \mathrm{C}$ $\left(41.0^{\circ} \mathrm{F}\right)$ and secondary browning assessed visually after $21 \mathrm{~d}$ storage at the same temperature using the same scale as in Fig. 5. Error bars (where visible) represent $\mathrm{SE}$ of the mean, $\mathrm{n}=8$.

subsequently treated with the $\mathrm{ABS}$ was depleting some of the ascorbic acid and thus reducing the efficacy of the ABS on the slices.

\section{Conclusions}

This work demonstrates that a low-volume spray system for applica- tion of anti-browning solution can effectively control cut-edge browning and reduce the severity of microbially induced secondary browning in freshcut apple slices. Addition of a natural antimicrobial such as vanillin can further reduce the severity of secondary browning. Together these results suggest that the fresh-cut apple slice industry should investigate the use of low-volume spray units for washing and treating slices, since there appears to be a measurable benefit in terms reduction in the incidence and severity of secondary browning.

\section{Literature cited}

Beuchat, L.R., B.V. Nail, B.B. Adler, and M.R.S. Clavero. 1998. Efficacy of spray application of chlorinated water in killing pathogenic bacteria on raw apples, tomatoes and lettuce. J. Food Protection 61:1305-1311.

Clement, D.B. 2004. Fresh-cut fruit category to top $\$ 1$ billion by 2008 . Fresh Cut, July:1-3.

Delaquis, P., P. Toivonen, K. Walsh, K. Rivest, and K. Stanich. 2004. Chlorine depletion in sanitizing solutions used for apple slice disinfection. Food Protection Trends 24:323-327.

Fitzgerald, D.J., M. Stratford, M.J. Gasson, and A. Narbad. 2005. Structure-function analysis of the vanillin molecule and its anti-fungal properties. J. Agr. Food Chem. 53: 1769-1775.

Gil, M.I., J.R. Gorny, and A.A. Kader. 1998. Responses of 'Fuji' apple slices to ascorbic acid treatment and low-oxygen atmospheres. HortScience 33:305-309.

Kupferman, E. 2002. Observations on harvest maturity and storage of apples and pears. Revised: Fall 2002. Postharvest Info. Network, Washington State Univ.-Tree Fruit Res. and Ext. Ctr., Wenatchee. 15 Nov. 2005. <http://postharvest.tfrec.wsu. edu/EMK2000A.pdf>.

López-Malo, A., S.M. Alzamora, and A. Argaiz. 1995. Effect of natural vanillin on germination time and radial growth of moulds in fruit-based agar systems. Food Microbiol. 12:213-219.

Toivonen, P.M.A. and T.H.J. Beveridge. 2005. Maturity, ripening and quality relationships, p. 55-77. In: O. Lamikanra, S.H. Imam, and D.O. Ukuku (eds.). Produce degradation: Reaction pathways and their prevention. CRC Press, Boca Raton, Fla.

Toivonen, P.M.A. and J.R. DeEll. 2002. Physiology of fresh-cut fruits and vegetables, p.91-123. In: O. Lamikanra (ed.). Fresh-cut fruits and vegetables: Science, technology, and market. CRC Press, Boca Raton, Fla.

Toivonen, P.M.A., P. Delaquis, M. Cliff, T. Beveridge, and L. Moyls. 2003. Development of apple quality standards for slicing and optimization of sanitation procedures: Final report, p. 119-128. In: 2003 Apple postharvest research review. Washington Tree Fruit Res. Commission, Wenatchee. 